First published in The Pharmaceutical Journal $2^{\text {nd }}$ November 2018, DOI: 10.1211/PJ.2018.20205670.

Available at: https://www.pharmaceutical-journal.com/opinion/correspondence/pharmacists-needa-formulary-for-the-aviation-industry/20205670.article?firstPass=false 


\section{Pharmacists need a formulary for the aviation industry}

Those working in community pharmacy may be familiar with the same faces and camaraderie, but those working in an airport pharmacy will have a different set of customers and patient groups to consider. One such group is airline pilots, who have very specific needs - in particular, the need to operate an aeroplane safely.

The aviation industry has led the way in safety, with the introduction of automation, standard operating procedures, checklists, and training and development - all of which have been extrapolated to other disciplines, such as pharmacy and medicine. The study of human factors and fatigue in aviation is now attracting research; do pharmacists also need to consider the effect of medicines - prescribed or over-thecounter — on a pilot's ability to do their job safely?

Aviation authorities have dedicated medical teams that regulate medication use. Pilots should contact an aeromedical examiner (AME) for any medical condition. However, pilots do not always contact their GP or AME for minor ailments. Could pilots be reluctant to expose their condition and risk the possible consequences for their licence?

In 2015, the General Aviation Joint Steering Committee noted that $40 \%$ of the 200 fatal air accidents they studied involved the pilot taking some form of drug. Pharmacists must consider not only the side effects of the medicines they supply, but also their interactions with other medicines that the pilot may be taking. Pilots should be made aware that some medicines can cause cognitive impairment, even if the pilot feels normal. And pilots should not fly until a set period of time has elapsed after taking over-the-counter medicines, such as sedating antihistamines, pain medicines, certain dietary supplements and decongestants.

A study by Kingston University, which investigated pharmacist and pilot perceptions of each other's roles in aviation medication safety, highlighted that more needed to be done to improve awareness and safety ${ }^{[1]}$. Before flying, nearly one-third (31\%; $n=48$ ) of pilots surveyed had used pseudoephedrine, which may have affected performance, given the drug's potential to cause insomnia and dizziness.

The study also highlighted a disagreement about who was responsible for ensuring that the pharmacy consultation is tailored to the patient's profession. Pharmacists stated that they were not aware of pilots' needs; and both pilots and pharmacists agreed that guidelines for pharmacists would be helpful.

Pharmacists need a formulary to guide them on the specific medicines that pilots can and cannot take. This formulary could also apply to other professions requiring high levels of safety and concentration. 
Philip Crilly, pharmacy teaching fellow, Kingston University

Amir Anwar, pharmacist, Kingston University

Reem Kayyali, professor, Kingston University

Lluís Vallverdú, former senior lecturer, Kingston University; pharmacist; airline captain

\section{References:}

[1]Anwar A. A formulary for the aviation industry - is there a need? Unpublished dissertation. London: Kingston University; 2016. 